\title{
A dialectical approach to the systematic analysis of geovisual communication using Bertin's visual variables
}

\author{
Francis Harvey \\ Leibniz Institute for Regional Geography, Leipzig, Germany
}

\begin{abstract}
:
This presentation presents a dialectical approach for the analysis and synthesis of geovisual communication systems using the graphic variables of Jacques Bertin as the primary analytical structure. This approach to studying geovisual communication accounts for its dynamics and interaction. It builds primarily on semiotic concepts advanced by Roland Barthes and Umberto Eco that emphasize the interactions between author and reader and the cultural circulation of knowledge. It relies on a Kantian critical epistemology to move beyond an instrumental description of a graphics-based system of communication. The visual system of affordances made and understood with a geovisualization produces situative meaning involving signification and interpretation, which is neither static nor discrete, but transforms what is known and what can be known. These conclusions lead to theoretical insights related to prior discursive concepts of visual communication and raise some questions for future research about the socio-cognitive affordances of cartographic visualization. A practical example shows the empirical approach and initial validation.
\end{abstract}

\section{Visual Variables Structure Communication}

The seminal contributions of Roland Barthes point to the process of embedding visual meaning regarding sign, signifier, signified, sign and concept as an extension to Saussure's dyadic approach as two semiological systems, which accounts for the importance of Saussure's bar in the communication of meaning. The two systems code the knowledge of communication, accounting for the situatedness of meaning and its discursive making that connects a sign to a cultural context. Umberto Eco goes beyond Pierce's icon, index, and symbol trichotomy of a sign through an ongoing chain of interpretative referrals. This approach starts with an active collaboration between creator and reader. It can involve multiple circumstances, cultural aspects and evolve. Visual variables structure communication in an ongoing process.

The signification of a visual variable is analogous to an atom in a communication process. The analysis of the visual variables of a graphic element in a communication systems sense commences with an analysis of these visual variables related to individual elements and complex symbols. Barthes' functions, actions, and narrative offer a valuable framework. A synthesis follows that considers the epistemological aspects of a partial system and what its functions purport to do and what they actually do. The analytically determined relationships can be synthesized into webs of explicit and implicit meanings associated with Barthes' structure. This combination and visual intermingling of graphic representations in a geovisualization broaden then to consider their interactions and associations with creator and reader. The visual encompasses the semiotic communication of meaning. The dialectical and critical consideration of the relations and the structure of the communication leads to an improved comprehension of the affordances manifest in the graphical communication system. It also begins to account for mental aspects of perception.

\section{A model of geovisual communication?}

The theory and methods of this semiotic approach involve considering Bertin's graphical variables as elements of a model that corresponds to the communication system. Further, the structure of the geovisualization can be modeled symbolically to take up the questions how coding and decoding take place and made reliable given the dynamics of communication and the reliance on conventions in most cartography. This presentation closes with a summary of the benefits of a semiotic approach to the analysis and teaching of geovisual communication.

Keywords: cartographic communication, semiotics, Bertin 